\title{
Do mito da tecnologia ao paradigma tecnológico; a mediação tecnológica nas práticas didático-pedagógicas *
}

\author{
Maria Rita Neto Sales Oliveira
}

Centro Federal de Educação Tecnológica de Minas Gerais

\section{Introdução}

Inicialmente, gostaria de mencionar alguns aspectos tomados como ponto de partida para o conteúdo a ser aqui abordado. Em primeiro lugar, tenho como preocupação não apenas retomar estudos já realizados sobre o tema em diversos fóruns de discussão, tais como os Grupos de Trabalho da ANPEd. Sem desconsiderar tais estudos, porquanto defendo que o conhecimento é histórico e social, além de prático, pretendo apresentar algumas reflexões mais recentes em torno da temática. Além disso, as opções feitas e a abordagem do conteúdo aqui apresentado implicam, obviamente, concepções e posições que assumo sobre a matéria e têm como ponto de partida o que o tema proposto sugere: tomar a tecnologia como foco central de nossas discussões.

* Trabalho apresentado no GT Didática, durante a $24^{\mathrm{a}}$ Reunião Anual da ANPEd, realizada em Caxambu-MG, de 7 a 11 de outubro de 2001

\section{Da expressão mediação para a expressão intermediações tecnológicas}

Inicialmente, importa registrar concepções de tecnologia, educação e da própria característica de mediação, tal como aqui defendidas.

Em uma perspectiva técnico-científica, tecnologia refere-se à forma específica da relação entre o ser humano e a matéria, no processo de trabalho, que envolve o uso de meios de produção para agir sobre a matéria, com base em energia, conhecimento e informação. Nesse sentido e conforme tenho defendido em outros estudos (por exemplo: Oliveira, 1999, 2000), a tecnologia refere-se a arranjos materiais e sociais que envolvem processos físicos e organizacionais, referidos ao conhecimento científico aplicável. No entanto, a tecnologia não é propriedade neutra ligada à eficiência produtivista, e não determina a sociedade, da mesma forma que esta não escreve o curso da transformação tecnológica. Ao contrário, as tecnologias são produtos da ação humana, historicamente construídos, expressando relações sociais das quais dependem, mas que também são influenciadas por eles. Os produtos e 
processos tecnológicos são considerados artefatos sociais e culturais, que carregam consigo relações de poder, intenções e interesses diversos.

Quanto à educação, entende-se que ela é um trabalho concreto de produção e reprodução social da existência humana, nas esferas material e espiritual, pelo qual os atores da situação pedagógica relacionamse entre si e com o mundo natural e social. Nesse trabalho, defendo o compromisso com a formação humana ligada à assimilação, construção e produção cultural e não apenas à transmissão de idéias, valores e conhecimentos. Nesse sentido, a educação escolar, articulada às bases materiais da sociedade e a outras práticas sociais com as quais se relaciona dialeticamente, é prática intencional transformadora. Dentro disso, a concepção de educação aqui assumida envolve o compromisso com a superação das relações de desigualdade, dominação, exploração e exclusão societárias.

Finalmente, a propriedade de mediação da tecnologia, tal como expressa na formulação do tema, implica sua situação em um conjunto de relações, de ações recíprocas, no interior das práticas didático-pedagógicas. No entanto, não é raro entender-se, sob a expressão mediação, relações lineares, determinismos e modelos conectivos entre os fenômenos aos quais se referem. Nessa perspectiva, mediação tecnológica poderia ser entendida como mera ponte estabelecida entre as práticas pedagógicas, entre aspectos delas, ou até mesmo entre essas práticas e outras práticas sociais, consideradas de forma independente umas das outras.

Talvez essas questões pareçam superadas; entretanto, não é essa superação que tenho encontrado presente no discurso e na prática educacional, em diferentes tempos e espaços no país. Assim, considero importante, inicialmente, que o nosso entendimento da questão da tecnologia nas práticas didático-pedagógicas seja formulado pela expressão intermediações, justificando o subtítulo: "da expressão mediação para a expressão intermediações tecnológicas”, no tratamento da tecnologia nas práticas didático-pedagógicas.

\section{D o recurso tecnológico e das hipóteses da tecnologia educacional revisitada, do modelo de competência e do mito da tecnologia à superação dos problemas, reducionismos e limites nelas presentes}

Embora, por razões óbvias, não pretenda me estender acerca do tema da tecnologia educacional tratada, particularmente no Brasil, na década de 1970 e início da década de 1980, importa retomar o fato de que ela é marcada pela visão e crítica correspondente dos aparatos tecnológicos entendidos como recursos supostamente neutros a serem utilizados nas práticas didático-pedagógicas de sala de aula ou na organização do processo de trabalho pedagógico na escola.

Isso posto, da segunda metade da década de 1980 até a primeira metade da década de 1990, no período que antecedeu a aprovação da LDB de 1996, pode-se dizer que há refluxo da posição de defesa do uso das tecnologias como meios supostamente neutros nas práticas didático-pedagógicas e também refluxo das críticas a respeito. Mas a questão permanece, com ênfase, no âmbito das propostas e discussões ligadas agora à informática na escola e vinculadas principalmente aos centros-piloto de informática na educação, criados no segundo semestre de 1984 em cinco universidades do país.

Os educadores e professores que lidam com a área e as orientações das políticas públicas para ela organizam-se em torno da proposta de alternativas, não necessariamente excludentes, denominadas como: informática na educação (uso de recursos informáticos na gestão e administração escolar, na organização de dados na pesquisa educacional, ou nas exposições didáticas); informática educacional (uso de software para ensinar); e informática educativa (para caracterizar, em geral, os programas computadorizados interativos, no ensino, fundados no construtivismo piagetiano).

Essas alternativas consolidam-se, na segunda metade da década de 1990, quando a questão das tecnologias reaparece com uma nova força no contexto do trabalho escolar, quer no âmbito da sala de aula, propriamente dita, quer no âmbito da gestão e administração. Nessa 
condição, podem-se identificar o que denomino de hipóteses: da tecnologia educacional revisitada, do modelo de competência e do mito da tecnologia.

A hipótese da tecnologia educacional revisitada refere-se ao

[...] resgate da importância da tecnologia educacional, tal como defendida pelo tecnicismo pedagógico, mas tratada, agora, de forma diferente: - a partir de discussões relativas ao paradigma da empresa flexível e integrada; e (estreitamente ligado a isso) - em termos da consideração das tecnologias no trabalho escolar não apenas como método/recurso de ensino, (ou de gestão escolar), mas também como conteúdo/objeto de ensino.(Oliveira, 1999, p. 155).

Essa posição envolve a defesa da presença das novas tecnologias na escola, particularmente o microcomputador, na condução e na organização dos processos educativos com e para o uso da tecnologia, respectivamente nos casos em que: se utiliza o microcomputador como recurso didático ou as novas tecnologias organizacionais na administração (por exemplo: a Gerência da Qualidade Total - GQT); essas tecnologias são inseridas como componentes do conteúdo curricular nas escolas, com o objetivo de preparar o aluno para uma nova sociedade, cheia de tecnologias.

A posição descrita acarreta problemas quando, na defesa do domínio do aparato tecnológico por parte do aluno, em função do fato de o seu não domínio implicar um novo fator de desigualdade e exclusão societárias, não há a preocupação com o entendimento socioistórico desse aparato. Acarreta problemas também quando se desconhece que a transferência de métodos de gestão da produção na reestruturação pósfordista para o setor educacional e escolar está comprometida com a internalização das relações de produção, enquanto componente da inserção social. Dentro disso, os processos educativos e as relações sociais que se estabelecem na escola não são apenas formadores mais eficientes de novas qualificações, nem lidam apenas com o desenvolvimento de competências. De forma mais ampla, eles envolvem a construção de nova cultura, centrada em valores e objetivos da nova dinâmica da produção e do consumo.
Não se pode desconsiderar que as estratégias culturais e educacionais do novo capitalismo envolvem a construção de novas subjetividades, na formação de novos trabalhadores que não apenas demonstrem novos requisitos de qualificação, ou novas competências, mas que sejam viáveis segundo valores e objetivos do estágio atual de acumulação do capital. Dentro disso, os novos recursos e meios tecnológicos, no âmbito das práticas didático-pedagógicas, estão relacionados, também, com processos de mobilização de subjetividades.

Relacionada à anterior, a hipótese do modelo de competência identificaria a posição pela qual, com base no paradigma da empresa flexível e integrada, se defende a presença das tecnologias, na educação e no ensino, a partir do relacionamento entre educação e trabalho, mediado pela questão da exigência de um novo padrão de formação profissional, diante do uso de novas tecnologias no setor produtivo. Nesse sentido, defende-se o uso de novas tecnologias de cunho informacional nos processos escolares de formação de novos trabalhadores, que estariam sendo requeridos pelo estágio atual de desenvolvimento tecnológico, por um processo didático-pedagógico que não deveria e não poderia ser atrasado. (Oliveira, 1999, p. 152).

Essa posição implica problemas, reducionismos, quando assume a suposta generalização da reestruturação produtiva no país e a trata como destino e destituída de conflitos; quando afirma, de forma absoluta, a elevação e a mudança da natureza dos requisitos de qualificação do trabalhador, de quem estariam sendo requeridas novas competências; e quando equaciona as questões educacionais nos limites da modernização econômica e dos interesses empresariais.

Finalmente, em estreita relação com as hipóteses mencionadas e, a rigor, quase sempre presente em suas formulações, encontra-se a hipótese do mito da tecnologia, ou seja, afirmar-se que o uso das novas tecnologias no ensino, particularmente o microcomputador, garante melhorias na aprendizagem e no desenvolvimento do aluno. Essa posição é denominada de mito da tecnologia, uma vez que implica a ilusão de se atribuir aos recursos tecnológicos um valor acima das suas 
possibilidades de influência na melhoria do processo ensino-aprendizagem (Oliveira, 1999, p. 153).

No entanto, no interior dessa posição, lida-se, de forma contraditória, com a natureza atribuída à tecnologia. Esta teria caráter quase sagrado e perene, demandando celebração. Ao mesmo tempo, teria caráter efêmero, pelo qual a tecnologia é entendida como uma mercadoria, para ser consumida e trocada, em um mercado competitivo e integrado. Este ponto é problemático, sobretudo quando se ignora também que os novos aparatos tecnológicos informacionais não são destituídos de cultura, de linguagem, de reconceptualizações do espaço e do tempo, e que imprimem as características próprias de sua lógica, por exemplo, nos conteúdos de ensino com os quais lidam.

Em síntese, as visões apresentadas envolvem limites quando não expressam, na teoria e na prática, o entendimento da tecnologia em termos do contexto mais amplo do novo modo de desenvolvimento, no estágio atual de acumulação capitalista. Isto tem a ver com o entendimento do denominado novo paradigma tecnológico.

\section{Das hipóteses ao paradigma tecnológico}

No novo modo de desenvolvimento, a fonte de produtividade encontra-se na tecnologia da informação, ou seja, na geração de conhecimentos, de processamento de informação e de comunicação de símbolos. A rigor, conhecimentos e informação são fundamentais em todos os modos de desenvolvimento. No entanto, no novo modo de desenvolvimento, o diferencial é o fato de a principal fonte de produtividade ser a ação de conhecimentos sobre os próprios conhecimentos. A partir daí, pode-se dizer que este é um modo de desenvolvimento informacional, constituído por um novo paradigma tecnológico.

Com base na trilogia de Manuel Castells: A sociedade em rede (2000b), O poder da identidade (2000a) e Fim de milênio (1999), ${ }^{1}$ são características desse novo paradigma: a) a sua matéria-prima é a in-

${ }^{1}$ Para uma crítica ao trabalho de Castells, ver Demo (2001). Segundo este autor, Castells: possui uma visão americanizada do formação; b) possui ampla penetrabilidade, ou seja, o efeito das novas tecnologias é penetrável em todos os processos da existência individual e coletiva, pois a informação é parte integral de toda atividade humana; c) implica convergência e interdependência tecnológicas, resultantes da lógica compartilhada entre diferentes tecnologias, na geração da informação; d) relaciona-se à lógica de redes e, ligado a isso, implica flexibilidade, capacidade de reconfiguração das organizações, que são aspectos decisivos em uma sociedade caracterizada por constante mudança e fluidez organizacional. Nesse sentido, as tecnologias da informação viabilizam mudança de regras, sem destruir uma dada organização, visto que a base material desta pode ser reprogramada e reaparelhada.

Para a discussão do tema, importa lembrar ainda que esse novo paradigma tecnológico é apropriado para as relações capitalistas de produção baseadas: na globalização, no trabalho e na empresa voltados para a flexibilidade; na política destinada ao processamento instantâneo de novos valores e humores públicos; em uma organização social que lida com a superação do tempo e do espaço de lugares, e com a reorganização das relações de poder e de interações entre identidades culturais, sem ameaças à estrutura social vigente.

Dentro do exposto, as novas tecnologias da informação, no designado capitalismo informacional, estão integrando o mundo em redes globais de instrumentalidade, gerando as comunidades virtuais, no espaço de fluxos. No entanto, em um mundo de fluxos globais de riqueza, poder e imagens, há a tendência da construção da ação social e de políticas em torno de identidades primárias, enraizadas no tempo e no espaço de lugares. Nesse sentido, surgem novos sujeitos e novas identidades, pelas quais os atores sociais se reconhecem, com base em atributos culturais inter-relacio-

conhecimento e entende-o em seu caráter de aplicação e não como uma categoria em si; desconhece a crise do emprego e o caráter excludente da economia intensiva de conhecimento; desconhece, também, a intenção de competitividade presente na defesa neoliberal da educação de qualidade. 
nados, que prevalecem sobre outras fontes de significado e experiência. Presencia-se, assim, uma oposição fundamental entre o instrumentalismo universal abstrato e as identidades particularistas, historicamente enraizadas, ligadas, por exemplo, a raças, etnias, crenças, nações.

Dessa forma, em um entendimento amplo do novo paradigma tecnológico, junto aos processos de transformação tecnológica e econômica, não se podem desconsiderar as transformações culturais, propriamente ditas. Elas envolvem relações de gênero, raça, etnia, movimentos sociais de defesa pelos direitos humanos, movimento ambientalista, entre outros, no bojo de resistências à nova ordem global. Nos estudos sobre as interdeterminações tecnológicas nas práticas didáticopedagógicas, importa que haja espaços para as discussões das relações entre ser e rede.

$\mathrm{E}$, dentro disso, importa registrar pelo menos dois pontos. Primeiro, em um mundo de desigualdade e exclusão societárias, em que há poucas oportunidades, não apenas no espaço dos fluxos, mas também no espaço dos lugares, para os não-iniciados em computadores, para os não-atualizados com as novas tecnologias informacionais, constrói-se uma lógica de exclusão dos próprios agentes da exclusão. Assim, em oposição à rede, reafirmam-se velhas e constroem-se novas identidades culturais. Estas resistem a sua discriminação e excluem a rede, elas próprias, ou se integram a ela, por meio de atividades marginais aos valores assumidos pelo sistema social mais amplo. De fato, a realidade virtual e o tempo intemporal no novo paradigma tecnológico, em escala global, não destroem a especificidade da história, da cultura e das instituições territorializadas, que reagem diferentemente às novas tecnologias da informação.

Segundo, as interdeterminações entre tecnologia, sociedade e cultura, e entre tecnologia e as práticas didático-pedagógicas não são construídas em termos de atributos materiais bons ou maus da tecnologia. Obviamente esta não é neutra, mas as propriedades das matrizes de interação entre as forças tecnológicas, construídas pelos seres humanos, e eles próprios, individual ou coletivamente considerados, porquanto não são questões de destino, devem ser submetidas a estudo e investigação.

Retomando, então, o tema das tecnologias nas práticas didático-pedagógicas no país, no interior do novo paradigma informacional, importa tecer alguns comentários sobre o Livro verde (Brasil, 2000). Este contém as metas e o conjunto de ações do Programa Sociedade da Informação, ligado ao Ministério da Ciência e Tecnologia do País, cuja execução envolve o período do ano de 2001 até 2003.

O objetivo do Programa é acelerar a introdução das tecnologias informacionais na empresa brasileira, para alavancar o desenvolvimento da economia, em sua inserção na sociedade internacional e no sistema econômico mundial. Ao lado disso, o Programa compromete-se com a universalização dos benefícios da sociedade da informação e o uso crescente dos meios eletrônicos para gerar uma administração eficiente e transparente. Assim, sua finalidade está referida a "integrar e coordenar o desenvolvimento e a utilização de serviços avançados de computação, comunicação e informação e de suas aplicações na sociedade" .

Breve análise do documento, à luz das considerações feitas, sugere que a fundamentação do Programa equilibra-se entre uma dupla posição. De um lado, advogam-se benefícios econômicos da sociedade da informação, vista como uma realidade global; mostramse os seus riscos entendidos, apenas, no domínio das relações de distribuição, consumo, ou apropriação diferencial da riqueza, gerada pelos novos meios tecnológicos, considerados, eles mesmos, uma riqueza; e evidencia-se, enfim, uma visão tecnocrática e de determinismo econômico. De outro, defendem-se a construção de uma sociedade mais justa, fundada na riqueza da diversidade e identidade cultural; a efetiva participação social como sustentáculo da democracia; e a sustentabilidade de um padrão de desenvolvimento, que respeite as diferenças e busque o equilíbrio regional.

Quanto ao lugar da educação no Programa, ela aparece fundamentalmente como meio para impulsionar a sociedade da informação no país. Com isso, encontram-se as propostas de: a) tratamento das novas 
tecnologias como um recurso, apontando-se para a necessidade de serem superadas antigas deficiências do sistema educacional, ainda ligadas ao analfabetismo, e de serem criadas competências requeridas pela nova economia. Nesse sentido, é valorizada a educação à distância, com o uso de tecnologias da informação, cujo uso contribuiria, ele mesmo, para a familiarização e o acesso dos educandos em relação aos novos meios tecnológicos; b) tratamento das novas tecnologias como um conteúdo do sistema educacional, para prover a alfabetização digital, a aplicação de tecnologias e a geração de novos conhecimentos.

No entanto, causa perplexidade a seguinte afirmação, no Livro verde: "Há argumentos no sentido de que, para países em desenvolvimento, a capacidade de absorver novas tecnologias e de colocá-las em aplicação é tão ou mais importante do que a capacidade de gerar essas tecnologias". Ao lado disso, a educação é entendida como um processo de formação para a cidadania, que exige acesso à informação e ao conhecimento e à capacidade crítica para processá-los.

Por todo o exposto, no que diz respeito às intermediações entre tecnologia e educação, o Programa vai ao encontro de contradições também presentes, por exemplo, na atual reforma da educação profissional no país, a qual busca equilibrar-se sobre a polarização: "um projeto democrático de formação de cidadania calcado na igualdade e liberdade, aproximando-se de uma proposta de educação tecnológica para todos, e um projeto de modernização calcado na eqüidade e voltado para o mercado, que se distanciaria dessa proposta". (Oliveira, 2000, p.46.).

\section{À guisa de conclusão: algumas implicações}

A partir do exposto, deve-se buscar ultrapassar os problemas aqui apontados. Isso implica, necessariamente, o reconhecimento de que a presença das tecnologias da informação e da comunicação na educação e, particularmente, dos recursos da internet: a) não é em si um fator de equalização social, nem uma condição suficiente ou mesmo necessária para a formação crítica e criativa do aluno; b) está "conectada" com o modo de desenvolvimento informacional, com a denominada sociedade do conhecimento, que não se pauta por valores de justiça e inclusão social, democratização dos bens materiais e simbólicos construídos, sim, pelo esforço coletivo; c) em conseqüência, não lida com recursos tecnológicos neutros e não viabiliza o acesso ao universo de conhecimento da humanidade. Cabe lembrar, no mínimo, que o conhecimento não está disponível para todos, porquanto envolve vantagem comparativa, e mais: conhecimento de ponta é objeto de patente. As características da sociedade do conhecimento nem sempre se relacionam à democratização do saber. Assim, o barateamento dos recursos tecnológicos e a sua oferta no cenário educacional cumprem funções mais ligadas ao consumo do que à intenção de construção da cidadania e respeito aos direitos humanos; d) envolve novos problemas ligados a questões éticas, de segurança e de propriedade intelectual.

Deve-se buscar também propor a informática como objeto de estudo e não apenas como recurso de ensino-aprendizagem. Esse estudo deveria ser informado por pesquisas na área que investiguem: a) a questão do próprio uso da informática na educação, a partir da experiência e práticas não desenvolvidas pela defesa a priori de que esse uso está relacionado à melhoria do processo ensino-aprendizagem e à aprendizagem significativa; b) a cultura da informática, salientando-se as propriedades dos recursos informacionais, não reduzidas à questão da racionalidade computacional e sua analogia com a racionalidade humana. Importa pesquisar, por exemplo, características da linguagem da informática, não entendida apenas em seus aspectos lógicos, mas, sobretudo, em seus aspectos de interação, que definem tribos diferenciadas de usuários; c) a cultura da informática e suas relações com a cultura escolar e outros universos culturais. Cabe perguntar: em que medida o uso, por exemplo, da internet favorece a construção de uma perspectiva intercultural na escola ou o fortalecimento de posturas monoculturais ou de preconceitos em relação à cultura dos diferentes, ou, ainda, em que medida o uso da internet implica uma cultura diferente, no entrecruzamento das culturas na escola? 
Deve-se ainda estudar, nos processos de educação à distância mediada pelo computador: a) a relação da flexibilização do tempo para as atividades de ensino- aprendizagem com questões de intensificação do trabalho docente; b) as novas características do papel do professor e dos processos de avaliação.

Deve-se, finalmente, lidar com os recursos tecnológicos da sociedade do conhecimento de forma crítica, o que envolve o entendimento de que: a) esses recursos estão inscritos nas relações capitalistas de produção, num contexto de redefinição da teoria do capital humano, que é reconceptualizado, nas novas organizações, como capital intelectual; b) esses recursos articulam-se com questões atuais do desemprego estrutural e subemprego; c) no entanto, o conhecimento e o desenvolvimento tecnológico são forças materiais também na concretização de valores que se relacionam com os interesses dos excluídos, contradizendo os valores próprios da acumulação capitalista; d) em todo o contexto discutido, a educação assume papel crucial na socialização e construção do conhecimento e da cultura, podendo ultrapassar o caráter instrumental do conhecimento, tendo em vista a formação de cidadãos comprometidos com: a democracia, a igualdade e a inclusão sociais; a tolerância e o diálogo intercultural.

MARIA RITA NETO SALES OLIVEIRA é professora adjunta do Centro Federal de Educação Tecnológica de Minas Gerais (CEFET-MG) e professora titular aposentada da Faculdade de Educação da Universidade Federal de Minas Gerais. Publicou: A reconstrução da didática; elementos teórico-metodológicos. ( $3^{\mathrm{a}}$ ed.
Campinas: Papirus, 2000); 20 anos de ENDIPE (em V. M. F. Candau. Didática, currículo e saberes escolares. Rio: DP\&A, 2000); A pesquisa em didática no Brasil (em S. G. Pimenta. (org.). Didática e formação de professores; percursos e perspectivas no Brasil e em Portugal. $3^{\text {a }}$ ed. São Paulo, Cortez, 2001). Organizou, em colaboração com C. Ferreti e J. R. Silva Júnior, Trabalho, formação e currículo (São Paulo, Xamã, 1999). Pesquisa atual: “A prática pedagógica no ensino tecnológico e a noção de competência.E-mail: mariarita@dppg.cefetmg.br

\section{Referências Bibliográficas}

BRASIL, Ministério da Ciência e Tecnologia, (2000). Livro verde. (www.socinfo.org.br).

CASTELlS, M., (1999). Fim de milênio. São Paulo: Paz e Terra (vol. 3: A era da informação: economia, sociedade e cultura). , (2000a). O poder da identidade. $2^{\mathrm{a}}$ ed. São Paulo: Paz e Terra (vol. 2: A era da informação: economia, sociedade e cultura). , (2000b) A sociedade em rede. $3^{\mathrm{a}}$ ed. São Paulo: Paz e Terra (vol. 1: A era da informação: economia, sociedade e cultura).

DEMO, P., (2001). Educação e conhecimento; relação necessária, insuficiente e controversa. $2^{\mathrm{a}}$ ed. Petrópolis: Vozes.

OLIVEIRA, M.R.N.S., (1999). Tecnologias interativas e educação. Educação em Debate, Fortaleza, n. 37, p. 150-156.OLIVEIRA, M.R.N.S., (2000). Mudanças no mundo do trabalho: acertos e desacertos na proposta curricular para o ensino médio (Resolução CNE 03/98). Diferenças entre formação técnica e formação tecnológica. Educação \& Sociedade, Campinas, n.70, p. 40-62, abril. 
mais ligados aos movimentos sociais, que recorrem dominantemente à teoria social e à antropologia e os autores mais ligados a questões pedagógicas, que tendem a se apoiar na teorização de currículo, na teoria crítica, nos estudos culturais e no pensamento pósmoderno e pós-estrutural.

\section{Recent scientific production on} curriculum and multiculturalism in Brazil (1995-2000): advances, challenges and tensions

This article presents an analysis of recent Brazilian scientific production on curriculum and multiculturalism. It examines articles published between 1995 and 2000 in the following journals: Cadernos de Pesquisa, Revista Brasileira de Educação, Educação \& Realidade, Educação \& Sociedade e Educação em Revista. It also focuses on papers presented at the Annual Meetings of ANPEd during the same period. The study aims at identifying the main themes and arguments, the most significant theoretical influences, the methodological procedures employed, the contributions and the gaps. The tensions and challenges observed in the articles are also discussed. The paper insists on the importance of a dialogue between those authors more closely associated with social movements who are chiefly influenced by social theory and anthropology and those authors more closely associated with curriculum and pedagogy who are influenced by critical theory, cultural studies, post-modernism and post-structuralism.

Iria Brzezinski e Elsa Garrido

Análise dos trabalhos do GT Formação de Professores: o que revelam as pesquisas do período 1992-1998

O texto analisa setenta trabalhos apresentados no GT Formação de Profes- sores da ANPEd, no período19921998. As pesquisas foram organizadas segundo cinco descritores: formação inicial de professores, formação continuada, práticas pedagógicas, profissionalização docente e revisão da literatura sobre formação de professores. $\mathrm{O}$ estudo procura oferecer uma visão compreensiva sobre as questões, os referenciais teóricos e os avanços do conhecimento na área, explorando relações, explicitando divergências e delineando tendências de pesquisa. $\mathrm{O}$ conjunto dos trabalhos traz contribuições para fundamentar e subsidiar propostas e políticas de formação e de desenvolvimento profissional docente.

\section{Papers presented in the Working Group on Teacher Formation - what the research in the period 1992-1998 reveals}

This texts sets out to analyse seventy papers presented in the ANPEd Working Group on Teacher Formation during the period 1992-1998. The research was organised employing five categories: initial teacher formation, continued formation, pedagogical practices, teacher professionalisation and literature review on teacher formation. The study seeks to offer a comprehensive vision with regard to theoretical frameworks and recent advances in the area, exploring relations, expressing divergences and outlining research tendencies. The set of papers offers contributions to substantiate proposals and policies for teacher formation and professional development.

\section{Maria Rita Neto Sales Oliveira}

Do mito da tecnologia ao paradigma tecnológico; a mediação tecnológica nas práticas didático-pedagógicas O objetivo principal do texto é apresentar uma visão crítica da tecnologia no âmbito da educação e do ensino.
Aborda três hipóteses sobre a matéria: tecnologia educacional revisitada, modelo da competência e mito da tecnologia, evidenciando seus problemas, reducionismos e limites. Em sequiência, discute as características do novo paradigma tecnológico, e alguns aspectos do Livro verde do Ministério da Ciência e Tecnologia do país. Como conclusão, levanta algumas implicações da necessária superação dos problemas apontados, para o entendimento e tratamento crítico das tecnologias nas práticas didático-pedagógicas.

From the myth of technology to the technological paradigm: technological mediation in pedagogical practices The main objective of the text is to present a critical perspective on technology in education and teaching. Three hypotheses are discussed: educational technology revisited, the competence model and the myth of technology. The text also discusses the characteristics of the new technological paradigm and some aspects of The green book published by the brazilian Ministry of Science and Technology. In conclusion, the article points to some of the implications linked to a critical understanding and treatment of technology in teaching and educational practice.

Bernardete Angelina Gatti

Reflexão sobre os desafios da pósgraduação: novas perspectivas sociais, conhecimento e poder $\mathrm{O}$ artigo salienta as diferenças entre o momento histórico em que os programas de mestrado e doutorado foram criados e o momento atual. Discute-se o papel social desses cursos na dicotomia conhecimento $x$ poder e o dilema a ser enfrentado por mestrados e doutorados que vêm sendo instados, pela sociedade, a abrir-se a novas modali- 